\title{
The Canadian Hospitals Injury Reporting and Prevention Program (CHIRPP) in the UK: a pilot study
}

\author{
DH Stone, NV Doraiswamy
}

\begin{abstract}
Objectives-To assess the feasibility, strengths and weaknesses, and preventive utility of the Canadian Hospitals Injury Reporting and Prevention Program (CHIRPP) in a paediatric setting in the UK.
\end{abstract}

Design-Implementation and operational evaluation of CHIRPP.

Setting-A paediatric accident and emergency department in Glasgow, Scotland, UK.

Methods-CHIRPP forms were used to collect and analyse data on the circumstances, mechanisms, and types of injuries in 2516 children (age range 0-13 years) presenting to the accident and emergency department over the period of 1 April 1993 to 31 January 1995. The strengths and weaknesses of CHIRPP were assessed by direct observation, discussion with staff, operation of the CHIRPP software, and scrutiny of the output.

Results-After initial technical problems, CHIRPP ran smoothly. Although parental compliance was high, staff compliance was low, and this resulted in a low capture rate. Tabulations indicated the potential of the system for identifying both hazardous environments and vulnerable population subgroups at whom specific preventive measures can be targeted. Specific proposals for enhancing the efficiency and preventive utility of CHIRPP in this setting were formulated.

Department of Child Health, University of Glasgow and Department of Public Health Medicine, Greater Glasgow Health Board, UK DH Stone

Accident and Emergency Department, Yorkhill NHS Trust, Glasgow and University of Glasgow, UK NV Doraiswamy

Correspondence to: Dr DH Stone, Paediatric Epidemiology and Epidemiology and Community Health (PEACH) Unit, Departmen of Child Health, University flasgow, Yorkhill Hospital, Glasgow G3 8SJ UK.
Conclusions-CHIRPP offers hospitals, public health departments, and government agencies in the UK a promising tool for planning national, regional, and local injury prevention.

(Injury Prevention 1996; 2: 47-51)

Keywords: surveillance, CHIRPP, UK.

The prevention of accidental injury is a governmental priority in both England ${ }^{1}$ and Scotland. ${ }^{2}$ The authors of a recent literature review emphasised the importance of high quality in targeting interventions, and in evaluating outcomes. ${ }^{3}$ Accident and emergency departments are the 'missing link' in the range of local data in stimulating interest in the subject, sources currently generating data on injuries in the National Health Service. ${ }^{4}$

Other parts of the world, notably Scandinavia, ${ }^{5}$ Australia ${ }^{6}$ and North America, ${ }^{7}$ have taken the lead in establishing local injury surveillance systems. In 1990, building on the pioneering work of the Australian National Injury Surveillance and Prevention Project (of which local schemes, such as the Victoria Injury Surveillance System ${ }^{8}$ were part), the Canadian government launched a system of its own. This was known as CHIRPP - the Canadian Hospitals Injury Reporting and Prevention Program ${ }^{9}$ - and used software (subsequently modified) provided by the Australian Ministry of Health. Initially, CHIRPP comprised a centrally coordinated network of 10 children's hospitals. It has since been extended to include five general hospitals. Each participating hospital has its own designated staff who oversee the data collection. CHIRPP is funded and managed nationally by the Laboratory Centre for Disease Control (LCDC) in Ottawa, a Directorate (in the Health Protection Branch) of Health Canada. The LCDC maintains and analyses the database containing all the information collected by the participating hospitals, provides technical support, and publishes a regular newsletter. ${ }^{9}$

The purpose of the present study was to investigate the feasibility of installing and operating CHIRPP in a UK setting, to assess its practical strengths and weaknesses, and to identify ways of maximising its usefulness for injury prevention.

\section{Methods}

A senior member of the LCDC visited the Royal Hospital for Sick Children, Glasgow (the only children's hospital in the region and one of the largest in the UK) to supervise the installation of the CHIRPP software and the training of a dedicated clerical officer. The medical, nursing, and clerical staff of the accident and emergency department were briefed on the objectives of the pilot study which started on 1 April 1993.

The protocol for data collection was as follows. Each serially numbered CHIRPP form - a double sided A4 questionnaire - was distributed on arrival to the parents or accompanying adults of children (ages 0-13 years) attending the accident and emergency department with an injury (excluding return visits for the same injury). They were asked to complete the first side of the form containing a few simple 
questions about the injury including location, circumstances, mechanism, car seating position (in the case of an injured occupant), and whether any consumer product or safety equipment was involved. Answers were recorded by the respondents in free text form. This usually took less than three minutes. The attending physicians required about 20 seconds to complete the reverse side containing questions on the anatomical site, nature, intentionality of the injury, and the disposal of the patient.

The completed forms were deposited at a designated collection point. They were uplifted once daily, checked, and processed by the specially trained clerical officer. This involved alpha numeric coding of the responses at the time of data entry on to the computer. Only forms that had been fully completed on both sides were entered on the database. The CHIRPP software was then used to generate a series of standard tabulations.

The operation of CHIRPP at each stage, from installation to reporting, was reviewed critically by the authors using a combination of direct observation, discussion with accident and emergency department staff, the operation of the software to generate tables, and scrutiny of the output for its preventive potential.

\section{Results}

(1) EXPERIENCE OF INSTALLING AND OPERATING CHIRPP

After the recruitment and training of a full time clerical officer to code and enter the data, the immediate practical requirements were for a dedicated microcomputer and for a secure office equipped with adequate power points and a telephone. These were obtained after a period of negotiation with the management of the hospital. The total cost of installing and operating CHIRPP was modest, with expenditure required only to employ the clerical officer, to purchase the computer, and to cover routine running costs.

The CHIRPP form was minimally modified before being printed to take account of local requirements (such as the postcode of residence). The possibility of attaching the form to the clinical record was considered but rejected for administrative reasons.

The CHIRPP software, comprising a suite of programs written in a fourth generation computer language, SCULPTOR, is essential for the coding and entry of the data as well as for interrogating the database. Initially, problems were encountered in the operation of this software, particularly in the generation of tables. Most of these were solved with the assistance of the CHIRPP centre in Ottawa and by the transfer of the system on to a more powerful (486-DX) computer. Actual coding problems were few and usually trivial.

To preserve confidentiality, only the first three letters of the surname were entered on the computer. This, along with a form serial number and the date of birth, was sufficient for data handling purposes.
(2) PRACTICAL ASPECTS OF COLLECTING CHIRPP DATA

The purpose and nature of the data collection were explained (both verbally and in writing) to the parents or accompanying adults by either the receptionist or triage nurse. A few (less than $2 \%$ of attenders) did not complete the first side of the CHIRPP questionnaire for a variety of reasons. Some parents were understandably distracted by anxiety about their injured child. A few had already been asked to participate in another survey (for clinical audit purposes, for example) being conducted at the same time in the accident and emergency department. Other reasons for parental non-compliance included illiteracy, non-availability of reading glasses, lack of familiarity with English, and preoccupation with accompanying siblings. Most parents, however, expressed enthusiasm for completing the CHIRPP form upon being made aware of its preventive objective.

The main difficulty encountered was staff resistance. The accident and emergency department clerical staff appeared to perceive CHIRPP as an unwelcome addition to their routine workload. The compliance of these workers with the requirement to distribute the forms to the parents of all injured children was consistently low. Their stated reasons included a shortage of clerical personnel, compounded by frequent staff turnover, and a lack of time. The net result of these administrative problems, combined with the initial decision (since reversed) to process only fully completed forms, was that data collection occurred erratically. This was particularly so at nights, weekends, and holidays (when the incidence of injury is high) when a skeleton staff were on duty.

Staff objections to CHIRPP could not be dismissed lightly. While seemingly a trivial task, closer scrutiny of the CHIRPP data collection revealed a fairly complex series of steps. First, the receptionist had to assess whether the child was eligible. Second, the form had to be located and attached to a clipboard along with a functioning ballpoint pen, and a one page explanation of the purpose of the exercise and the right of the parent to decline to participate. Third, the form had to be handed to the parent with a verbal explanation. Fourth, the form had to be transmitted to the appropriate physician for completion of the reverse side. Finally, the form had to be deposited in a special tray for uplifting, checking, and processing. A failure at any one of these stages was liable to cause a breakdown of the entire process.

Other factors also conspired to prevent efficient data collection. It became apparent that staff were unable to distribute forms to the parents of those injured children who were admitted directly to the wards from other hospitals, or who, because of the severity of their injuries, required resuscitation or admission to the intensive therapy unit. Moreover, approximately one third of the distributed forms were not processed either because of incompleteness (of either side) or because they 
simply went missing. Some were subsequently retrieved from waiting areas, treatment rooms and corridors, while others were found lodged in case records.

Medical staff displayed an initial reluctance to complete the form, mainly because of their perception of the project as narrowly focused research, but this was gradually overcome by the institution of formal briefing sessions at the start of each new intake of medical officers at six monthly intervals.

Consequently, data on only a small proportion of the anticipated number of injured children were captured by the system in the first few months of its operation. Improvement has since been obtained by constant staff exhortation, encouragement and feedback of data, and by tranferring the primary responsibility for issuing the forms from the receptionists to the nurses, especially those responsible for triage. The number of forms processed has risen steadily since the start of data collection (figure). The capture rate for the study period as a whole was estimated at around $15 \%$ of eligible patients. A more precise figure is difficult to calculate owing to the lack of a reliable denominator.

(3) OUTPUT

Tables 1-3 are selected analyses of the 2516 cases entered on the database over the period 1 April 1993 to 31 January 1995. These are presented for illustrative purposes only because they are based neither on a total nor a representative population sample. The tables indicate, however, the potential usefulness of the data for identifying age - and gender -

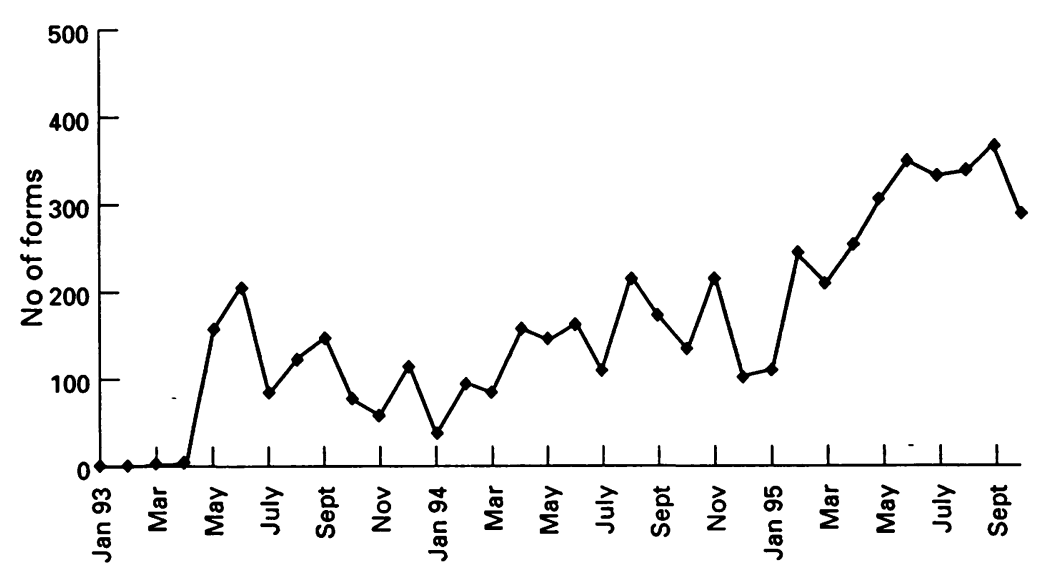

January 1993-October 1995

Numbers of CHIRPP forms processed per month. specific population subgroups in which injuries occur most frequently and for describing the location of the injury events (table 1), their circumstances and mechanisms (table 2 ), and their clinical presentations and anatomical sites (table 3). Further tables on disposal, day and time of incident, as well as cross tabulations (of, for example, age groups by 'disposal' category) may also be produced. In addition to quantitative data, qualitative analyses (not shown) of the narrative texts using key words or phrases can be generated from the database for indepth investigation of the circumstances of specific injuries.

To encourage those involved in the data collection, as well as to provide feedback to the public, these tabulations were transformed into graphs, pie charts, and histograms which were distributed to clinical and administrative staff in the hospital.

\section{Discussion}

Few injury surveillance systems have been implemented or evaluated in the UK. The best known is probably the product oriented Home and Leisure Accident Surveillance System (HASS and LASS) of the Department of Trade and Industry. ${ }^{10}$ This comprises a network of participating general hospitals, most of which treated only a small minority of injured children in their areas, and only one of which is located in Scotland. While the HASS/LASS data have proved extremely valuable, their major limitation is their unsuitability for local injury surveillance. The proposed minimum data set for accident and emergency departments in England ${ }^{11}$ is likely to prove inadequate for targeted paediatric injury prevention given the inability of such an approach to generate data with sufficient detail about causal factors.

Of the various available injury surveillance systems that collect detailed causal information, CHIRPP has been developed in cultural, linguistic, and health care settings in Australia and Canada that are similar to those of the UK. Both its face and content validity are high. This pilot study has now demonstrated that injury surveillance by means of CHIRPP, while feasible in a UK paediatric hospital, is likely to achieve its full potential only if a high level of staff compliance can be ensured.

CHIRPP has both strengths and weaknesses. Its advantages include its 'off the shelf' availability, its use of narrative text to describe the events leading to the injury, its simplicity and brevity, its high rate of parental compliance, and its sophisticated computer prog-

Table 1 Cases of age, gender, and location of incident

\begin{tabular}{|c|c|c|c|c|c|c|c|}
\hline Age group (years) & $\begin{array}{l}\text { No }(\%) \\
\text { males }\end{array}$ & $\begin{array}{l}\text { No }(\%) \\
\text { females }\end{array}$ & $\begin{array}{l}\text { No with } \\
\text { unknown gender }\end{array}$ & Total No $(\%)$ & $M: F$ ratio & Location & No $\left({ }^{o}{ }_{o}\right)$ \\
\hline $\begin{array}{l}0-4 \\
5-9 \\
10-14 \\
\text { Other/not known }\end{array}$ & $\begin{array}{c}639(42 \cdot 9) \\
509(34 \cdot 2) \\
318(21 \cdot 4) \\
22(1 \cdot 5)\end{array}$ & $\begin{array}{c}427(42 \cdot 4) \\
343(34 \cdot 0) \\
221(21 \cdot 9) \\
17(1 \cdot 7)\end{array}$ & $\begin{array}{l}8 \\
6 \\
4 \\
2\end{array}$ & $\begin{array}{c}1074(42 \cdot 7) \\
858(34 \cdot 1) \\
543(21 \cdot 6) \\
41(1 \cdot 6)\end{array}$ & $\begin{array}{l}1.5 \\
1.5 \\
1.4 \\
1.3\end{array}$ & $\begin{array}{l}\text { Residential } \\
\text { Educational } \\
\text { Transport } \\
\text { Outdoor/sport } \\
\text { Other }\end{array}$ & $\begin{array}{r}1253(49 \cdot 8) \\
503(20 \cdot 0) \\
383(15 \cdot 2) \\
212(8 \cdot 4) \\
165(6 \cdot 6)\end{array}$ \\
\hline All ages & $1488(100)$ & $1008(100)$ & 20 & $2516(100)$ & 1.5 & Total & $2516(100)$ \\
\hline
\end{tabular}


Table 2 Cases by 'breakdown' events and mechanism of injury

\begin{tabular}{lllr}
\hline 'Breakdown' events & No $\left({ }^{\circ}{ }_{0}\right)$ & Mechanism & No $\left({ }_{o}^{o}\right)$ \\
\hline Fall by victim & $1127(44 \cdot 8)$ & Mechanical & $2303(91 \cdot 5)$ \\
Being in proximity to danger & $625(24 \cdot 8)$ & Chemical & $149(5 \cdot 9)$ \\
Loss of control of objects/movement & $297(11 \cdot 8)$ & Thermal & $48(1 \cdot 9)$ \\
Acts by persons & $164(6 \cdot 5)$ & Asphyxiation & $8(0 \cdot 3)$ \\
Other/not known & $303(12 \cdot 0)$ & Other/not known & $8(0 \cdot 3)$ \\
Total & $2516(100)$ & Total & $2516(100)$ \\
\hline
\end{tabular}

Table 3 Cases by nature of injury and body part

\begin{tabular}{lclc}
\hline Nature of injury & No $\left({ }^{o}{ }_{0}\right)$ & Body part & No $\left(o_{o}\right)$ \\
\hline Cuts and lacerations & $509(20 \cdot 2)$ & Head & $779(31 \cdot 0)$ \\
Haematoma/bruising & $446(17 \cdot 7)$ & Upper extremities & $700(27 \cdot 8)$ \\
Sprain/strain & $325(12 \cdot 9)$ & Lower extremities & $467(18 \cdot 6)$ \\
Fracture & $287(11 \cdot 4)$ & Trunk and abdomen & $36(1 \cdot 4)$ \\
Systemic injury & $144(5 \cdot 7)$ & Sytemic & $144(5 \cdot 7)$ \\
Inflammation & $131(5 \cdot 2)$ & Other/not known & $390(15 \cdot 5)$ \\
Superficial abrasions & $116(4 \cdot 6)$ & & \\
Burn & $50(2 \cdot 0)$ & & \\
Other/not known & $508(20 \cdot 2)$ & & $2516(100)$ \\
Total & $2516(100)$ & Total &
\end{tabular}

ram. Above all, CHIRPP data offer a unique insight into the complex sequence of events leading to injury. This rich storehouse of information is invaluable for the development of appropriate preventive interventions that can be precisely targeted at vulnerable population subgroups or hazardous environments. Numerous examples of the exploitation of such data for public health purposes have emerged in recent years from both Australia $^{8}$ and Canada. ${ }^{9}$ Several clinical and public health colleagues have expressed interest in the data for research and service planning. The disadvantages of CHIRPP include its total reliance on the active cooperation of accident and emergency department staff, its dependence on a free standing, dedicated microcomputer that does not integrate easily with other information systems within the hospital, and its need for local technical support.

The principal challenge posed by any injury surveillance system is to find a means of integrating its operation and results into routine service activity. We encountered two obstacles to achieving this end, one conceptual and the other practical. First, the staff of the accident and emergency department tended to regard CHIRPP as a research project rather than as a core departmental function fulfilling an important obligation to the wider community. Consequently, staff priorities - particularly at busy periods of the day - were frequently perceived to lie elsewhere. Second, resource constraints placed an excessive burden on both clerical and clinical personnel. We employed one full time clerical officer (funded from a strictly time limited research grant) to code and enter the data on a computer located some distance from the accident and emergency department. The absence of a designated CHIRPP coordinator, supernumerary to the permanent establishment of clerical staff, who could assist in the all aspects of distribution, completion, and collection of the forms, was undoubtedly a major handicap.
These barriers to successful injury surveillance are, we believe, surmountable. As a result of this pilot study, we have formulated a number of relatively simple remedial measures that we will seek to implement. First, we will propose to the hospital management that CHIRPP ceases to be regarded as a pilot study and should become an integral (and obligatory) component of routine clinical record keeping. Second, we will widen the existing CHIRPP briefing sessions to include staff outwith the accident and emergency department who are responsible for the clinical care of injured children directly admitted to the wards, including the intensive therapy unit. Third, we will reinforce the feedback of CHIRPP data to accident and emergency department staff by presenting monthly injury figures in easily digestable visual format along with a brief commentary, and by emphasising the potential that this form of teamwork holds for prevention. Fourth, we will suggest the appointment of a CHIRPP coordinator located in the accident and emergency department to ensure a high capture rate of good quality data. This will be achieved by supporting clerical, nursing and medical staff in distributing, completing and collecting the forms, and by obtaining missing information retrospectively from case records or, where appropriate, by telephone interviews of parents. Fifth, we will disseminate CHIRPP data to interested colleagues, external agencies, and community groups to raise awareness and stimulate public health action. Finally, we will establish a small working group to oversee the progress of the program, monitor the quality of the data, interpret the analyses, identify priority areas for more detailed investigation and, where appropriate, preventive initiatives.

\section{Conclusion}

The ultimate test of any injury surveillance system is whether the data generated lead to the implementation of effective injury prevention measures. An injury surveillance system is, therefore, a necessary but insufficient precursor of injury prevention. The insights gained from the data must be translated into action, and this, in turn, depends on strong local multiagency commitment to prevention. The extent to which this occurs remains variable, partly because of the paucity of organisational research that can inform the development of appropriate administrative structures. The lack of such evidence, however, should not undermine the importance of high quality, locally based, causal data on injuries.

Our experience suggests that hospital based injury surveillance is both feasible and worthwhile providing staff can be motivated and supported to aim for the collection of data on all injured children. In our view, the key to success is to demonstrate the routine, service - rather than research or audit - function of CHIRPP by providing sufficient resources to compensate for the inevitable additional workload imposed on accident and emergency department staff. Through continuous encouragement, education, and feedback of results to the 
staff, we have obtained an almost threefold increase in the capture rate since the completion of this study in early 1995 (figure). Further improvement is likely to depend on our success in securing additional administrative resources.

We conclude that CHIRPP offers UK hospitals, public health departments, and government agencies a promising and relatively inexpensive tool for the planning, implementation, and evaluation of injury prevention measures at local, regional, and national levels.

We are grateful to the Greater Glasgow Health Board for their financial support of this pilot study, to the management of the Yorkhill NHS Trust for agreeing to host and support the study, and to the clerical staff, nurses, and physicians of the accident and to the clerical staff, nurses, and physicians of the accident and emergency department of the Royal Hospital for Sick Pless and Dr G Sherman of Canada for their encouragement and Pless and Dr G Sherman of Canada for their encouragement and support, and to the Laboratory Centre for Disease Control, Health Canada, for providing us with the CHIRPP software. Finally, we are deeply grateful to the children and parents who would not have been possible.
1 Department of Health. The health of the nation - a strategy for health in England. (Cm 1986.) London: Department of Health, 1992.

2 Scottish Office. Scotland's health - a challenge to us all. Edinburgh: HMSO, 1992.

3 Towner E, Dowswell T, Jarvis S. Reducing childhood accidents. The effectiveness of health promotion interventions: a literature review. London: Health Education Authority, 1993.

4 Deane $M$. Child accident data: accessible and available? $f$ Public Health Med 1993; 15: 226-8.

5 Schelp L. Community intervention and changes in accident pattern in a rural Swedish municipality. Health Promotion 1987; 2: 109-25.

6 Vimpani G. Injury surveillance: a key to effective control of childhood injuries. Australian Paediatric fournal 1989; 25: 10-3.

7 Guyer B, Gallagher S, Chang B, Azzara C, Cupples L Colton T. Prevention of childhood injuries: evaluation of the Statewide Childhood Injury Prevention Programme (SCIPP). Am f Public Health 1989; 79: 1521-7.

8 Ozanne-Smith J, Nolan T, eds. Hazard. (Volume 1, editions 1-10, 1988-92, Injury Data and Prevention.) Melbourne: Victorian Injury Surveillance System, 1993.

9 Canadian Hospitals Injury Reporting and Prevention Program. CHIRPP news. Issue 2. Ottawa: Bureau of Chronic Disease Epidemiology (Health Canada), July 1994.

10 Consumer Safety Unit, DTI. Home and leisure accident research. London: Department of Trade and Industry, 1992.

11 Department of Health. The health of the nation key area handbook - accidents. London: Department of Health 1993.

\section{Boy 5 , takes sister, 3 , for ride in family's van}

A 5 year old boy and his 3 year old sister went for a drive in their father's van - with the boy at the wheel. 'I had my seatbelt on, and so did by sister', the boy told nonplussed police after the outing, which miraculously ended without mishap, 'I'm not going to go to jail'.

The incident, reported by a local newspaper, occurred when the boy decided to take his sister out for breakfast early on a Sunday morning. Their parents were still asleep and the keys to the family van were on the buffet. The boy took the keys and drove nearly a kilometre on a normally busy artery, before stopping near a gas station. The 18 year old cashier at the gas station, recalls seeing a van 'that seemed to be moving itself, without a driver: I couldn't see anyone's head'. She watched as two children, clad in pyjamas, climbed out and walked toward the convenience store next door. The boy, she says, told her it was his truck, that they were on their way to McDonald's and that he was driving the van with his father's permission.

After interviewing the boy, police said they were told he drove by alternately standing up so he could see and lying down so he could reach the pedals, Police, when they first arrived at the scene thought the call was a prank. The boy's parents were stunned, police said (Canadian Press).

\section{A quadriplegic warns: don't take dumb risks}

The following is a letter to the editor of a Toronto newspaper, reprinted in its entirety:

Tragedy strikes again, but this time to someone who gets the front page of the Toronto Star (Deputy Premier Ernie Eve's son dies in crash, Oct 9). But let's not disguise the incident with the word "accident". Justin Eves and his friend crossed the stupid line. They took dumb risks instead of smart ones. Eves was not driving sober, and was not buckled up.

This was not an accident, defined as "an irreversible act of fate". This was carelessness at its best. I know. I'm a quadriplegic for doing the same thing eight years ago. Now I dedicate some of my time speaking to teenagers on how to take smart risks and prevent such tragic and unnecessary events.

I hope Justin's friends got on their knees in sorrow for letting their friend drive, and to thank God for sparing them'. Adrian M Dieleman, Richmond Hill (Toronto Star, 18 October 1995). 